\title{
Identification of inference fallacies in solid waste generation estimations of developing countries. A case-study in Panama
}

\author{
Jorge M. Torrente-Velásquez ${ }^{\mathrm{a}, \mathrm{b}, *}$, Maddalena Ripa ${ }^{\mathrm{a}}$, Rosaria Chifari ${ }^{\mathrm{c}}$, Mario Giampietro ${ }^{\mathrm{a}, \mathrm{d}}$ \\ ${ }^{a}$ Institut de Ciència i Tecnologia Ambientals, Universitat Autònoma de Barcelona, Bellaterra, Spain \\ ' Universidad Tecnológica de Panamá, Panamá

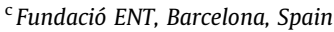 \\ ${ }^{\mathrm{d}}$ Institució Catalana de Recerca i Estudis Avançats, Barcelona, Spain
}

\section{A R T I C L E I N F O}

\section{Article history:}

Received 27 December 2019

Revised 21 December 2020

Accepted 22 March 2021

Available online 7 April 2021

\section{Keywords:}

Solid waste generation intensity

Estimation

Multilevel analysis

Inference fallacies

Meta-analysis

Developing countries

Panama

\begin{abstract}
A B S T R A C T
The absence of sound sampling procedures and statistical analyses to estimate solid waste generation in many developing countries has resulted in incomplete historical records of waste quantity and composition. Data is often arbitrarily aggregated or disaggregated as a function of waste generators to obtain results at the desired spatial level of analysis. Inference fallacies arising from the generalization or individualization of results are almost never considered. In this paper, Panama, one of the fastest-growing developing countries, was used as a case-study to review the main methodological approaches to estimate solid waste generation per capita per day, and at different hierarchical levels (from households to the country). The solid waste generation intensity indicator is used by the Panamanian waste management authority to run the waste management system. It was also the main parameter employed by local and foreign companies to estimate solid waste generation in Panama between 2001 and 2008. The methodological approaches used by these companies were mathematically formalized and classified as per the expressions suggested by Subramanian et al. (2009). Seven inference fallacies (ecological, individualistic, stage, floating population, linear forecasting, average population and mixed spatial levels) were identified and allocated to the studies. Foreign companies committed three of the seven inference fallacies, while one was committed by the local entity. Endogenous knowledge played an important role in these studies to avoid spatial levels mismatch and multilevel measurements appear to produce more reliable information than studies obtained via other means.

๑ 2021 The Authors. Published by Elsevier Ltd. This is an open access article under the CC BY license (http://
\end{abstract} creativecommons.org/licenses/by/4.0/).

\section{Introduction}

Waste generation rates are rising. There are currently about 2 billion metric tons of municipal solid waste produced annually worldwide. The World Bank (2018a) estimates overall solid waste generation (SWG) will increase to 3.4 billion metric tons by 2050. Most of this solid waste will be generated from developing countries due to their increasing population, economic growth and rapid urbanisation (Zohoori and Ghani, 2017).

Accurate data is required to have a deeper understanding of SWG behaviour in order to implement sustainable and feasible waste management policies (Bandara et al., 2007). Failure of sound SWG sampling and analysis may either over or under estimate the required capacity of waste treatment facilities and increase envi-

\footnotetext{
* Corresponding author at: Institut de Ciència i Tecnologia Ambientals, Universitat Autònoma de Barcelona, Bellaterra, Spain.

E-mail address: jorgemiguel.torrente@uab.cat (J.M. Torrente-Velásquez).
}

ronmental impact due to the implementation of ineffective measures (Buenrostro et al., 2001).

Common methodological shortcomings of SWG studies performed in developing countries include: uncertainty on the exact number of inhabitants generating waste in certain locations, unrepresentative samples of inhabitants to represent large populations, misallocation of population belonging to certain spatial levels, SWG data collection from multiple unreliable sources, incomplete historical record of quantity and quality of SWG, and use of old SWG data as updated data (Afon and Okewole, 2007; Wilson and Velis, 2014).

To mitigate these fallibilities, the SWG in developing countries is commonly obtained from the solid waste generation intensity (SWGI) indicator. The SWGI is the daily SWG of a determined spatial level or place, e.g. country, region, city, averaged over its population.

This indicator normalizes SWG per capita thus allowing its comparison among different places of equivalent spatial level 
(Linster, 2003). However, benchmarking this value among nonequivalent spatial levels generates inconsistencies in SWG studies and potentially makes solid waste management (SWM) plans technically unfeasible and economically unviable (DEFRA, 2013). Consequences are that SWM plans in developing countries are seldom implemented. Methodological approaches behind results are never publicly disclosed due to constraints of data disclosure, imposed by companies performing SWG studies. These studies become obsolete, new ones are then performed and the same pattern is repeated (Voss et al., 2013).

Inconsistencies derived from benchmarking SWGI values among non-equivalent spatial levels are mostly due to the misconception of the unit of observation and the unit of analysis. The unit of observation is at the level at which one observes, measures or collect the data. The unit of analysis is at the spatial level about one wish to say something, i.e., the focal level of the study. These levels can be the same, but they need not be. For instance, when data exists only at the municipal level and the objective is to understand the SWG behaviour of individuals, inferences may be drawn from the disaggregation of the data available. In this scenario, known as cross-level inference, a mismatch of observation and analysis levels occurs, thus potentially creating inference errors or fallacies (Alker Jr., 1974; Blakely and Woodward, 2000).

Inference fallacies are properly documented in epidemiology since Robinson's study made a seminal contribution by demonstrating that correlations for the same two variables can be different depending on the level at which they are analysed (Robinson 1950). As indicated by Molina-Azorín et al. (2019), most data come from phenomena where subjects form nested hierarchies. In this regard, there are two ways to study nested data: aggregation (obtaining data at a lower level and combining the values of those variables to the higher level) and disaggregation (data from higher-level units are disaggregated into data on a larger number of lower-level units). Either of these two strategies may produce errors when conclusions are drawn at the wrong level (MolinaAzorín et al., 2019).

The error due to aggregation is known as the 'ecological fallacy'. This fallacy occurs where inferences about individuals are drawn from inferences on the group to which they belong, thus deriving conclusions about individuals solely on the basis of group data analysis (Winzar, 2015). For instance, calculating the SWG at a country level with the aggregation of SWGI per capita, obtained from a sample population of a specific town, generates an ecological fallacy. Here, the value fails to take into account the population distribution across other parts of the country (Afon and Okewole, 2007).

The error due to disaggregation is known as 'atomistic or individualistic fallacy'. In this case, inferences about a group are based on data belonging to individual members of that group, thus deriving conclusions about the entire group solely on the basis of individual data analysis (Loney and Nagelkerke, 2014).

This paper identifies and compares typologies of SWGI estimations to detect ecological and individualistic fallacies committed. It also goes further and discusses new inference fallacies derived from flawed methodological approaches used for SWG surveying in three studies performed in Panama from 2001 to 2018. These studies were conducted by foreign (INECO and JICA) and local (GDR) companies which estimated the SWGI from SWG values at different hierarchical levels e.g. household, town, district (Guerrero et al., 2013).

\subsection{Going forward, the study is structured as follows:}

Section 2 provides an overview of the study area. It explains self-similarity of SWGI estimations and examines common sampling methods of SWG data. It also presents details on the SWG studies performed in Panama, displays typologies of SWGI estimations and identifies inference fallacies derived from their misuse.

Section 3 classifies the typology of SWGI estimated values from the SWG studies presented. It compares these values among them and against literature and discloses inference fallacies perpetrated by each analysed study. Finally, Section 4 concludes by discussing the uncertainties and the lessons learned from this study.

\section{Materials \& methods}

This section outlines the extent to which skewed multi-level population distribution produces self-similar SWGI estimations when approaching from broader spatial levels e.g. country- to more individual ones e.g. inhabitants. Panama serves as the casestudy area.

It also presents common SWG sampling approaches and introduces the measurement level as an intermediate spatial level to estimate SWGI values at the analysis level from values obtained at the observation level. It goes further to show how SWGI is locally estimated, how precise estimations are carried out within SWG studies and their mathematical formalization. Finally, it highlights typologies of SWGI estimations and fallacies derived from their misuse.

\subsection{Study area and SWGI self-similarity as per population distribution}

In the past decade, Panama has been one of the fastest-growing economies worldwide (INEC, 2016) and the highest Economic Annual Growth Rate country of Latin-America (IMF, 2018). In July 2018, Panama was re-classified from the upper-middle to the highincome level group of countries by the World Bank (2018b). This in itself is an indicator of economic affluence. The fast-increasing economic transition sharply contrasts with Panama's archaic waste management system struggling to react to the SWG derived from unsteady resource consumption habits (JICA, 2005; Ragossnig and Vujić, 2015).

Panama has around four million inhabitants. Like in most countries, the population is unevenly distributed throughout spatial levels, e.g. country, provinces, districts (Fig. 1a) (Fujimoto et al., 2015). Roughly, 37\% of the country's total population is concentrated in $15 \%$ of its area, which is the Panama province (PP). $71 \%$ of the population of PP is concentrated in $23 \%$ of its area which is Panama district (PD), while $5 \%$ of the population of PD is concentrated in $0.3 \%$ of its area which is Bethania Town (BT) and so on (INEC, 2006). This multilevel population distribution entails that the size of places is determined by additive population from subsets of places within them (Addison, 2000).

For instance, in Fig. 1b, as places approach from left to right to the level of the smallest SWG unit (inhabitant or individual), population within same-level places (e.g. from province to province, from community to community, from household to household) appears to have the same size, and the SWG of those places, that now depends on fewer individuals' values, derives on each time more self-similar SWGI estimations (Mandelbrot, 1967). For instance, the variation in family memberships between households is lower in comparison to the population variation between provinces. Therefore, resource consumption habits (and consequently SWG behaviour) will vary more from province to province than from household to household.

\subsection{Introduction of the measurement level from SWG sampling methods to estimate SWGI}

There are several methods to derive SWGI values at the analysis level from SWG values available only at the observation level. Fig. 2 
a)

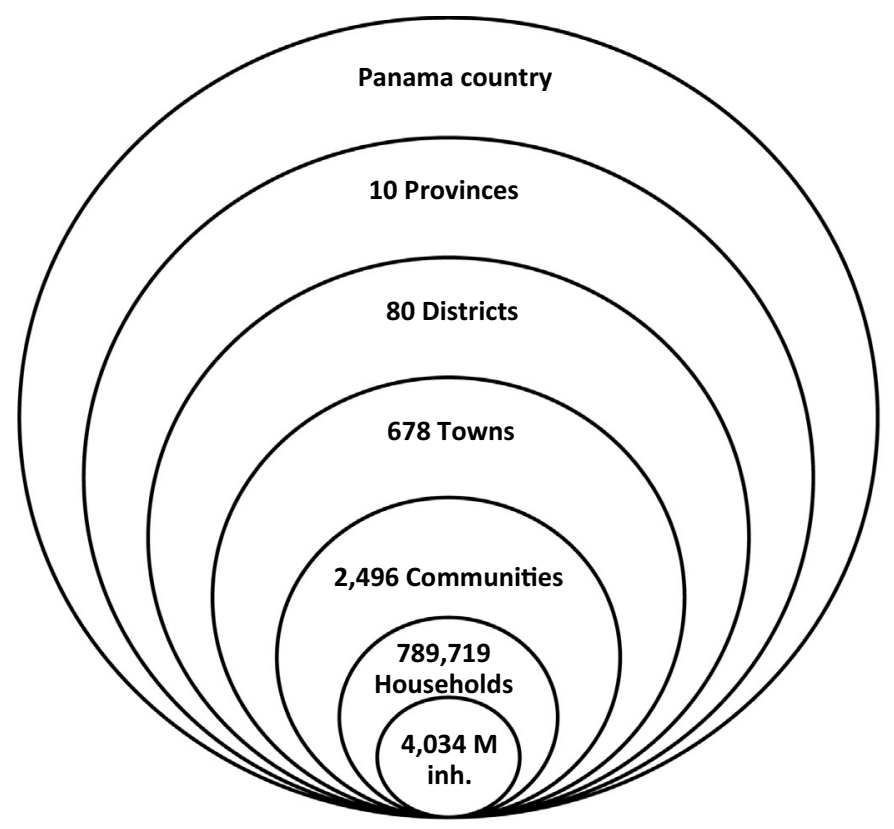

b)
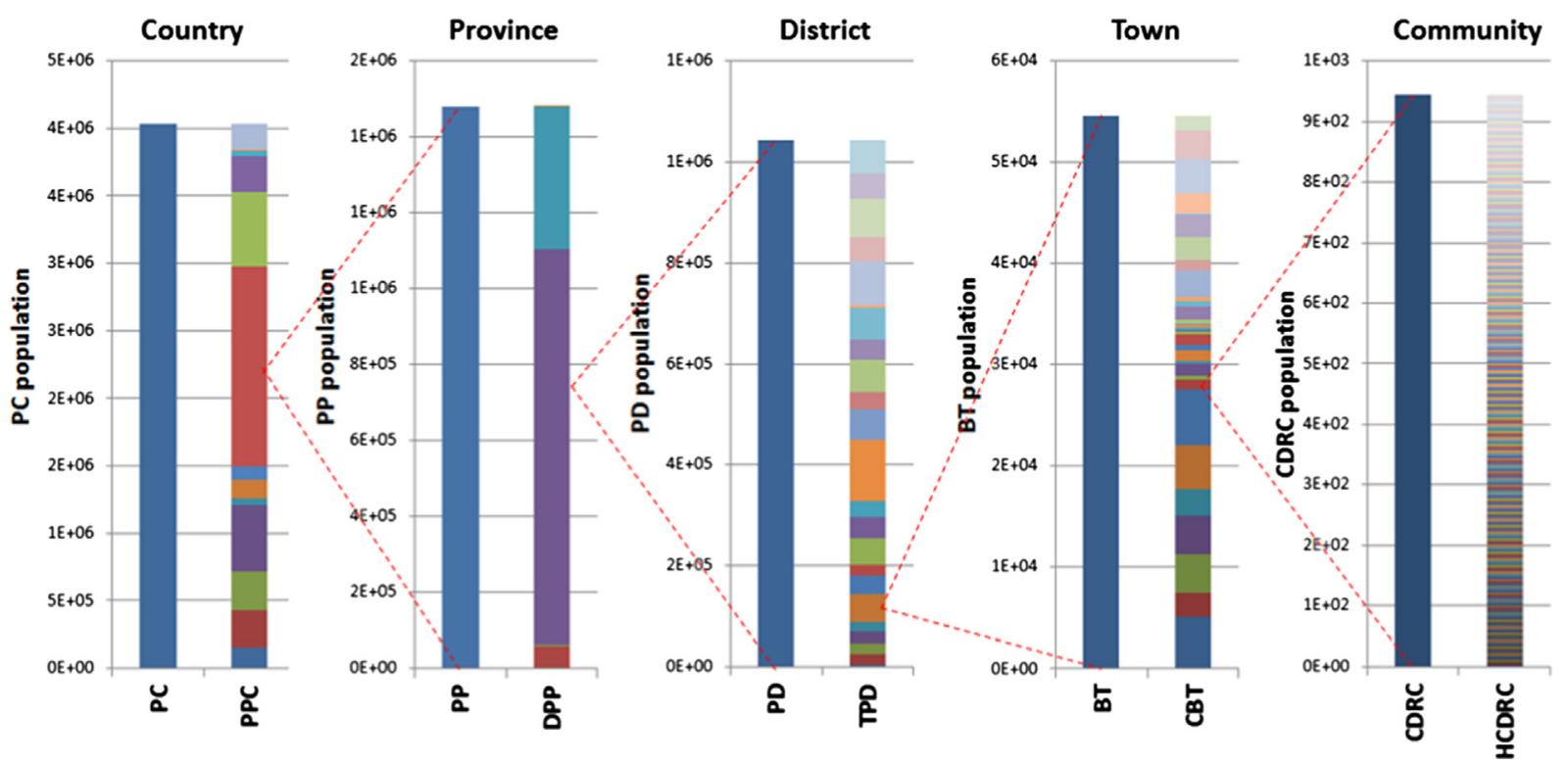

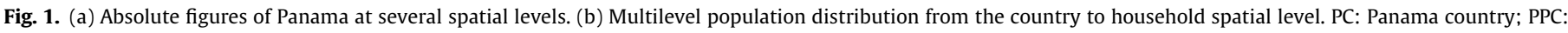

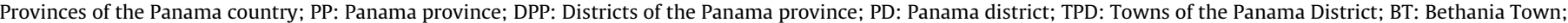
CBT: Communities of the Bethania Town; CDRC: Condado del Rey Community; HCDRC: Households of the Condado del Rey Community.

illustrates four methods to infer SWGI at the analysis level of Bethania, a town located in Panama district with a population of 50,000 .

Estimation (a) (upper-left side) would be inferred by obtaining SWG values of each household, then aggregating and averaging by the total population of the town. This method would be the most reliable SWGI estimation of Bethania because each household is being surveyed; however, the entire process is very cumbersome and expensive.

Estimation (b) (lower-left side) may obtain SWG values from a statistically representative sample of households located at a specific area of the town, instead of from all households. The downside with this method is that the results may be inaccurate because SWG behaviour may vary considerably between the sampled households and the rest of the population.

Estimation (c) (upper-right side) considers the SWG behaviour of households by clustering (Kohberger and Everitt, 1994) them according to a defined variable like income which reflects the resource consumption habits and the resulting SWG behaviour. In this case, statistically representative samples of households within each cluster are randomly selected for surveying and averaging their SWG. The SWGI of Bethania is obtained by averaging 


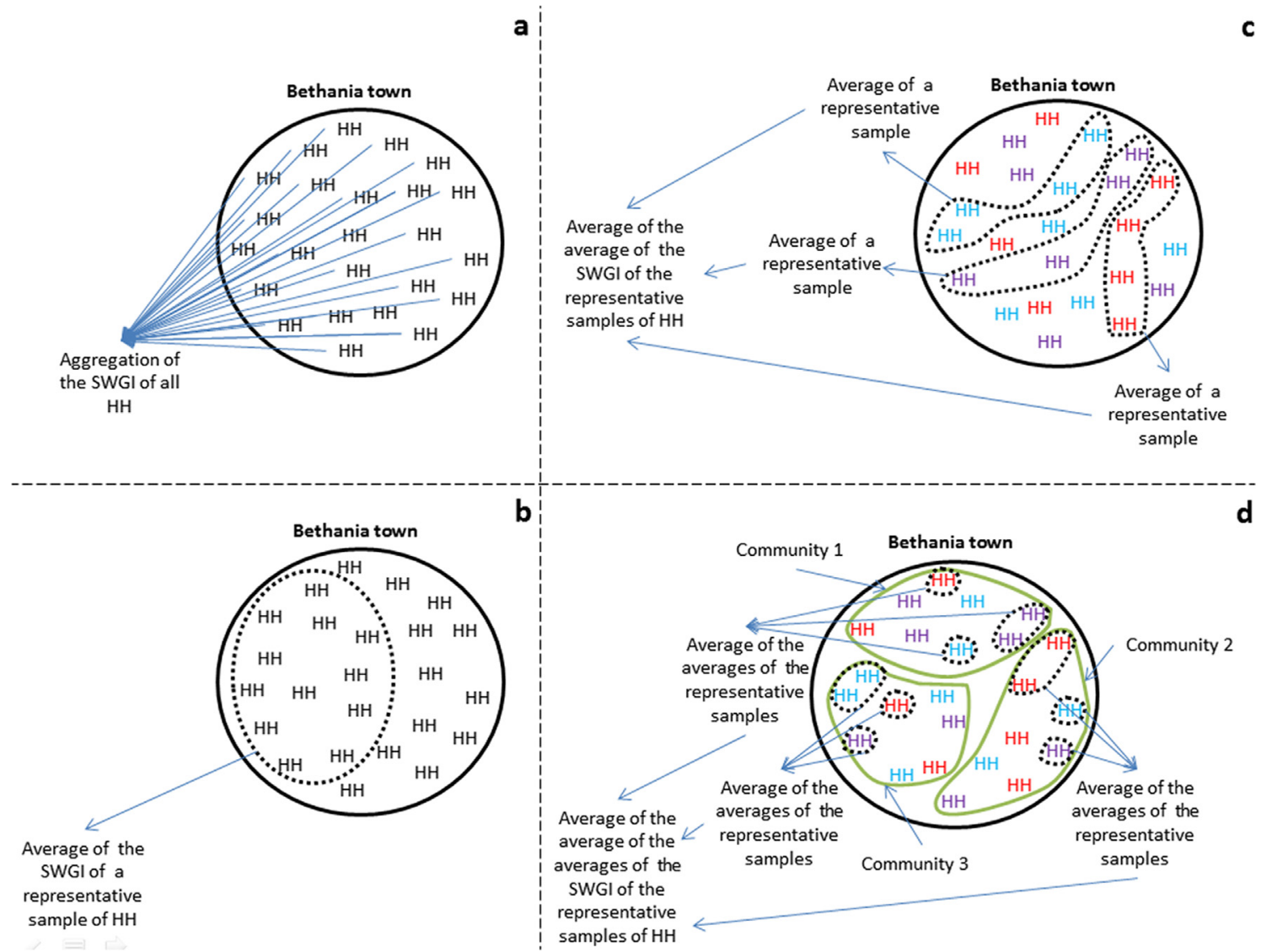

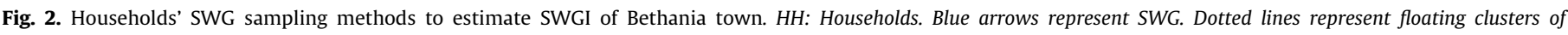

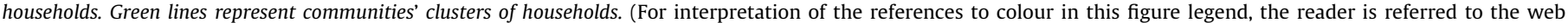
version of this article.)

the SWGI of each sample by their population, and then averaging resulting SWGI by total clusters created. However, clustering households without considering spatial distribution as per households' location produces floating clusters (Giampietro et al., 2009) that misses the causality of their SWG behaviour, necessary to assure reliability of the clustering process (Matuszewski, 2002).

Estimation (d) (lower-right side) introduces the measurement level to make it possible to consider spatial distribution as per households' location. The measurement level is a spatial level in between the analysis and observation levels. In Panama, groups of households constitute communities while groups of communities constitute towns. As shown in Fig. 2d, communities (green line surrounding households) are a geopolitically predefined group introducing context for households to be clustered taking into account SWG behaviour of the communities to which they belong. The use of the measurement level in this example allows inferring SWGI of the Bethania town by clustering households within communities and applying Estimation 3 within a known spatial level i.e., communities. This increases the reliability of the clustering process with the SWG behaviours defined by communities, as opposed to floating clusters of households, while keeping the process feasible.

\subsubsection{Measurement level selection affecting SWGI estimations}

The measurement level represents a geopolitically defined spatial level in between the analysis and observation levels. It gives robust context to places at the observation level to obtain reliable SWGI estimations at the analysis level. However, sometimes there are several measurement levels to choose from, where choosing one or another will affect the SWGI estimation.

Fig. 3 shows the extent to which choosing from three different measurement levels (secondary y-axes) i.e., town (Fig. 3a), community (Fig. 3b), and household (Fig. 3c) can change the average number of waste generating inhabitants at the analysis level (primary $y$-axes). This selection will determine SWGI estimations at different observation levels (x-axes) i.e., country, capital province, capital district, metropolitan towns, Bethania (as a stratified town) and communities of Bethania. Metropolitan towns are defined as a spatial sublevel between the levels of district and town, consisting of a set of urban towns of the capital district. Furthermore, Bethania has been named a stratified town since it contains a wide range of social classes, resource consumption habits, and SWG behaviours.

When observed from the country and capital province observation levels, SWGI estimated from average waste generating inhabitants at the town measurement level, presents an eight-fold difference (country and capital province bars of Fig. 3a). When SWGI is estimated from average waste generating inhabitants at the community measurement level, results at the country and capital province observation levels are much closer (country and capital province bars of Fig. 3b). The SWGI estimation from average waste generating inhabitants at the household measurement level presents almost the same results when observed from the country and province observation levels (country and capital province bars of Fig. 3c).

The closer the measurement level is to the analysis level (from Fig. $3 a-c)$, the more even and reliable the SWGI value across 


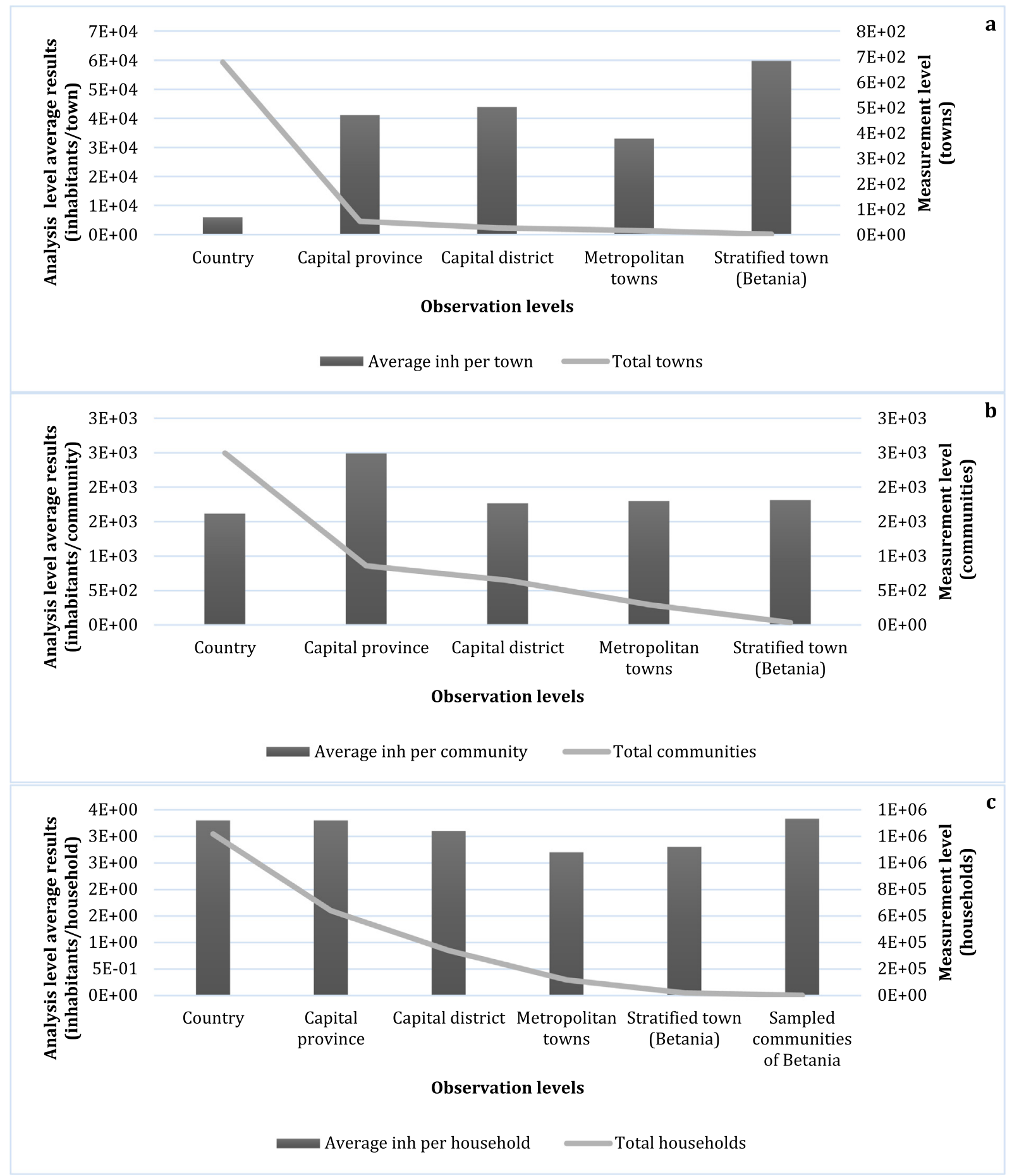

Fig. 3. Waste generating inhabitant of the analysis level at several observations levels by the measurement level of (a) towns, (b) communities and c) households.

observations levels is. Consequently, it becomes more technically unfeasible and economically unviable, due to lower spatial levels' constraints, to collect SWG data e.g., the need for more entities to collect data from in order to comply with statistical representative samples.

Grey lines of Fig. 3 represent variations in the quantity of measurement levels at each observation level. For instance, for the observation level "country" of Fig. 3a, the measurement level is towns, and the grey line indicates the number of towns at this observation level; a total of 678 that decreases to $<100$ at the "Capital province" observation level. The same is applied to the rest of observation levels of Fig. 3a, and to Fig. 3b and c. It should be noted that: as the measurement level from Fig. 3a-c i.e. towns, communities, households, respectively approaches the analysis level (inhabitants), selfsimilarity is more and more present among their SWGI estimated values because the number of inhabitants generating waste present fewer variations across observation levels (Nottale, 2010).

SWGI estimations are affected if measurement levels are not correctly defined, leading to the fallacies which will be discussed in this study. 


\subsection{SWGI estimations by the local authority and SWG studies performed}

\subsubsection{SWGI estimation by the national waste management authority}

The national waste management authority (Autoridad de Aseo Urbano y Domiciliar or AAUD), assumes that population at every observation level i.e. from households to country have a normal distribution with a default SWGI estimation of $1.3 \mathrm{~kg} \mathrm{inh}^{-1} \mathrm{~d}^{-1}$, that is aggregated by the population of the analysis level at which SWG is to be obtained (JICA, 2003). To update the number of inhabitants on the SWGI estimation, AAUD uses a compound annual population growth rate of $5 \%$ which is applied to population value of the 2010 census; Eq. (1) formalizes AAUD's approach.

$S W G I_{\text {AAUD }}=1.05 \times 1.3 \times P_{2010}(C Y-2010)$

where $S W G I_{\text {AAUD }}$ is the SWGI estimation used by AAUD, 1.05 is the $5 \%$ compound annual population growth rate, 1.3 is the generic SWGI value in $\mathrm{kg} \mathrm{inh} \mathrm{h}^{-1} \mathrm{~d}^{-1}, P_{2010}$ is the population as per 2010 national census and CY is the current year when SWGI is to be estimated.

From 2001 to 2018, three studies have been executed to: (i) estimate SWGI; (ii) evaluate the situation of the Panamanian SWM system; and (iii) develop a SWM plan with defined normative and competence frameworks.

\subsubsection{SWGI estimation by JICA}

From 2001 to 2003, the Japanese company Kokusai Kogyo., ltd., representing the Japanese International Cooperation Agency (JICA), carried out the "Study on the Solid Waste Management for the Municipality of Panama in the Republic of Panama 2003-2015" (JICA, 2003) at a \$2M cost. SWG values were obtained at the household observation level for 15 days to estimate SWGI at the district analysis level. Households were clustered by mixing two different measurement levels: communities and towns. JICA classified both levels as "town" without considering that communities are sublevels of towns and there are different factors influencing the SWG at each level. To keep things simple, the measurement level used by JICA will be referred to as "town" going forward.

Towns were clustered based on household "apparent" income level values. These clusters where determined by the physical location of the households, and not based on official income level values. No statistical sampling technic was used to select the number of households per cluster; twenty random households were chosen per cluster (JICA, 2005).

To estimate the SWGI, surveyed households' SWG values were expressed per unit of an unspecified average value of waste generating inhabitants per household.

The SWGI was estimated from households' clusters formed using apparent income level data rather than official income level values. Despite this fact, the average SWG contribution of each cluster was weighed based on official income level values i.e. 11\% for high-income level population, $46 \%$ for middle-income level population and $43 \%$ for low-income level population. JICA performed a linear forecast of SWGI values from 2003 -2015 suing population growth as the main parameter, without considering a possible change in SWG behaviors which could potentially distort such a linear forecast.

Eq. (2) mathematically formalizes the SWGI estimated by JICA and shows the aggregation of the weighted averages of SWGI results per cluster.

$$
\begin{aligned}
S W G I_{J I C A}= & 0.11\left(\frac{1}{n} \sum_{i=1}^{n} \frac{S W G_{i}}{P_{i}}+C I_{H I}\right)+0.46\left(\frac{1}{m} \sum_{j=1}^{m} \frac{S W G_{j}}{P_{j}}\right. \\
& \left.+C I_{M I}\right)+0.43\left(\frac{1}{p} \sum_{k=1}^{p} \frac{S W G_{k}}{P_{k}}+C I_{L I}\right)
\end{aligned}
$$

where SWGI IICA $_{\text {is }}$ the SWGI estimation that resulted from JICA study, $n$ is the total number of apparent high-income towns, $S W G_{i}$ the $S W G$ for the $i$ apparent high-income towns, $P_{i}$ the population in the $i$ apparent high-income towns, $\mathrm{CI}_{\mathrm{HI}}$ the confidence interval of the SWGI estimation for apparent high-income towns. The same nomenclature is used for middle and low-income towns with their respective weighed SWG contribution.

\subsubsection{SWGI estimation by INECO}

From 2015 to 2017, the Spanish public company INECO carried out studies in Panama to set up the "National Integral Waste Management Plan 2017-2027" (INECO, 2017) at a \$4.5 M cost. Their methodology involved defining countrywide towns as the observation levels of SWG and clustering them using geopolitically undefined places which INECO defined by socio-economic criteria i.e. economic level represented by the Human Poverty Index (HPI), average income per capita and level of agricultural activities. These places do not count as measurement levels according to the definition of measurement level given before; however, for the sake of simplification will be considered as such.

The SWM system of developing countries is commonly composed of roughly origin, transport, and final disposal management stages. Unlike other studies which used the origin stage to observe SWG, INECO got SWG from values of waste arriving to the final disposal stage Over 75 days, INECO collated SWG data from the Panama district landfill. However, this practice results in important misestimations because landfills serve several towns, and surveyed waste collection trucks had plied undefined routes and unclear origins at their arrival to landfills i.e. from several communities across various towns. This means that waste values collected at the final disposal stage actually account for Solid Waste Disposal (SWD) not SWG. For this reason, going forward, SWG values surveyed by INECO will be referred to as SWD. INECO attempted to correct this flaw by using a "correction coefficient" of 1.24 i.e., SWG $=1.24$ SWD, but this simplistic approach dismisses waste losses along waste collection routes from origin to final disposal, commonly caused by waste collection and transport flaws e.g., containerization absence in the origin, incomplete waste collection routes and unspecialized collection human resource.

SWGI values at the measurement level was estimated by dividing SWG values obtained at the observation level by the population of the clusters. Four clusters were obtained, and the per capita high-income level cluster was solely represented by Panama district and its SWGI estimation mathematically formalized in Eq. (3).

The SWGI value for the entire country (not shown in Eq. (3) for the sake of simplification) was obtained by aggregating SWGI estimated values from clusters and multiplying by the whole country population. Results were forecasted to 2027, not linearly but considering population growth and the changing SWG behavior.

$S W G I_{I N E C O}=1.24\left(\frac{\frac{\sum_{i=1}^{n} S W D_{i}}{\frac{1}{n} \sum_{i=1}^{n} P_{i}}}{n}\right)$

where SWGI INECO is the SWGI that resulted from INECO study, 1.24 the correction coefficient, $n$ is the total number of Panama district towns, $S W D_{i}$ the $S W D$ for the $i$ Panama district towns, and $P_{i}$ the population in the i Panama district town.

\subsubsection{SWGI estimation by GDR}

In 2018, the local company Gestion de Residuos (GDR) carried out "Dynamic characterization study of the Urban Solid Waste of Bethania town by community clusters according to its sociodemographic characteristics" (MUPA, 2018) at a $\$ 27 \mathrm{~K}$ cost. The methodology involved using the community measurement level to cluster and survey SWG values of random observation level households by 
their income level to estimate SWGI at the Bethania town analysis level - refer to Eq. (4). Four out of 26 communities were randomly selected to represent low, middle, upper-middle and high households' income levels, depending on the sample statistical representativity and the feasibility of surveying tasks. SWGI was estimated by dividing SWG by communities' population. GDR did not produce SWGI forecast.

$S W G I_{G D R}=\frac{1}{n} \sum_{i=1}^{n} \frac{\sum_{i=1}^{n} S W G_{i i}}{n P i}$

where $S W G I_{G D R}$ is the SWGI estimation that resulted from GDR study, $n$ is the total number of representative communities in Bethania town, $S W G_{i i}$ the $S W G$ of each representative community made up of the aggregation of the SWG of the households making up each community, averaged by the total amount of households in each community $n$ and the inhabitants $P_{i}$ of each household $i$.

\subsection{Typologies of SWGI estimations and main fallacies derived from their misuse}

By applying the approach suggested by Subramanian et al. (2009), "Typology of health and disease studies", Fig. 4a shows five mathematical expressions configuring observation and measurement levels to estimate analysis level SWGI.

Expression type (a) (upper-left side) takes an individualistic focus. It is performed by aggregating, at the measurement level, average SWG values obtained at the observation level. Then dividing by the total amount of analysis level waste generating entities i.e., inhabitants, or places in cases where SWGI is not to be expressed in "per capita" terms. It aims to represent the SWGI of entities belonging to the same observation level from the standpoint of the individual contribution of entities' samples at the analysis level (James, 1890). The generalization of SWGI estimations obtained from the type (a) expression to analysis levels of other observation levels, different from the ones to which waste generating entities belong, lead to the individualistic or atomistic fallacy. Here, it is assumed that a causal relationship exists between waste generating entities of different observation levels. Also, that the replication of SWGI estimations, obtained from the analysis level of a first observation level, to the analysis level of a second observation level is equally or more reliable than a SWGI estimation obtained from direct SWG data of the second observation level (Blakely and Woodward, 1999).

Expression type (e) (lower-right side) takes a generalizing focus and matches the observation and measurement levels so that collection and aggregation of SWG values can be performed at the same level. SWGI estimations are directly obtained by dividing by the total amount of waste generating entities of the analysis level. It intends to attribute to all waste generating entities the SWGI estimated value obtained from their large-scale contribution to the observation level (also the measurement level in this case), thus reflecting their SWGI estimation at the analysis level from their perspective as a whole group (Robinson, 1950). The individualization of SWGI estimations, obtained from the type (e) expression at certain observation level, to the individual basis of the analysis levels of another observation level, lend to the ecological fallacy. The term "ecological" refers to a large-scale context as per hierarchy of different spatial levels (Moon et al., 2005; Selvin, 1958). Idrovo (2011) propose three criteria for the identification of the ecological fallacy which must be integrally met for it to be determined. They have been applied to the context of SWG in this paper as follows: (a) SWGI estimation must be obtained from large-scale SWG data; (b) SWGI estimation must be inferred to different analysis levels than the one aggregated at the measurement level to obtain SWG; (c) and SWGI estimated from expression type (e) must be different from that estimated with expression type (a).
Expressions type (c) and (d) (lower-left side) cannot be specified on their own, they will either take the form of expressions types (a) or (e), respectively.

The expression type (b) (upper-right side) is a multilevel expression obtained by: (i) surveying SWG values at the observation level, aggregating them at several measurement levels and dividing by the total measurement levels used; (ii) for each measurement level used, an average SWG value is obtained by dividing the number of waste generating entities which constitute each measurement level used; and (iii) dividing the aggregation of each average by the total amount of measurement levels used to estimate SWGI at the analysis level. The expression type (b) aims to represent observation level values in analysis level terms (Alker Jr., 1974). This is possible by considering the input that every analysis level entity exerts in the SWGI estimation at the observation level from values surveyed directly at the measurement level. The expressions type (b) enhances the possibility for cross-level approaches that supports discerning about the relative contribution, of both analysis and measurement level, to results at the observation level when aggregating the SWGI estimation by total waste generating entities. The simultaneous assessment of many waste generating entities in the context of the measurement levels shaping their SWG behavior, allows for a better representation of the effect that selected measurement levels exerts in waste generating entities, given that their relation is mutually causal. This approach also supports a more comprehensive framework to understand the ways in which the measurement level could contextually affect the SWG of waste generating entities of the analysis level or, alternatively, waste generating entities of the analysis level could causally affect measurement levels (Subramanian et al., 2009).

\subsection{Practical example to illustrate SWGI estimation typologies}

A numerical example is shown in Fig. $4 \mathrm{~b}$ to demonstrate different SWGI per capita estimations using expressions of Fig. 4a. It presents a community (analysis level) consisting of 4 households (measurement level) with 5, 2, 3 and 4 inhabitants (observation level) each. $S W G_{i j}$ and $S W G_{i}$ represent random SWG values for inhabitants and households respectively; their aggregation is the actual total SWG value at the community level. SWGI estimations are shown in the lower square in the same order as presented in Fig. 4a. This simple example makes the best-case scenario feasible i.e., surveying actual number of inhabitants at each household and their SWG. It demonstrates the extent at which there are differences in the SWGI estimations. Results obtained from expressions types (c) and (d) match those obtained from expressions types (a) and (e), respectively. The extent to which expressions types (c) and (d) could be replaced by expressions types (a) and (e), respectively, depends on the more households to survey SWG from, which limit is imposed by technical feasibility and economic viability issues of the surveying process.

The result obtained from expression type (b) represents the highest SWGI estimation, which is preferable over other results to offset uncertainty arising in the SWG surveying process (Wittwer et al., 2008).

\section{Results and discussion}

The first part of the results classifies the typologies of SWGI values, estimated from the SWG studies presented according to Fig. 4a, and compares these values among them and also against literature. The second part discloses inference fallacies committed by each analysed study. 
a)

\begin{tabular}{|c|c|}
\hline$\frac{1}{n} \sum^{n} \frac{S W G_{i}}{P_{i}}$ & $\frac{\frac{\sum_{i=1}^{n} S W G_{i}}{n} \sum_{i=1}^{n} \frac{1}{P i}}{n}$ \\
\hline$\frac{\frac{\sum_{i=1}^{n} \sum_{j=1}^{m} S W G_{i j}}{\frac{1}{n} \sum_{i=1}^{n} P_{i}}}{n}$ & $\frac{\sum_{i=1}^{n} S W G_{i}}{\sum_{i=1}^{n} P_{i}}$ \\
\hline
\end{tabular}

b)

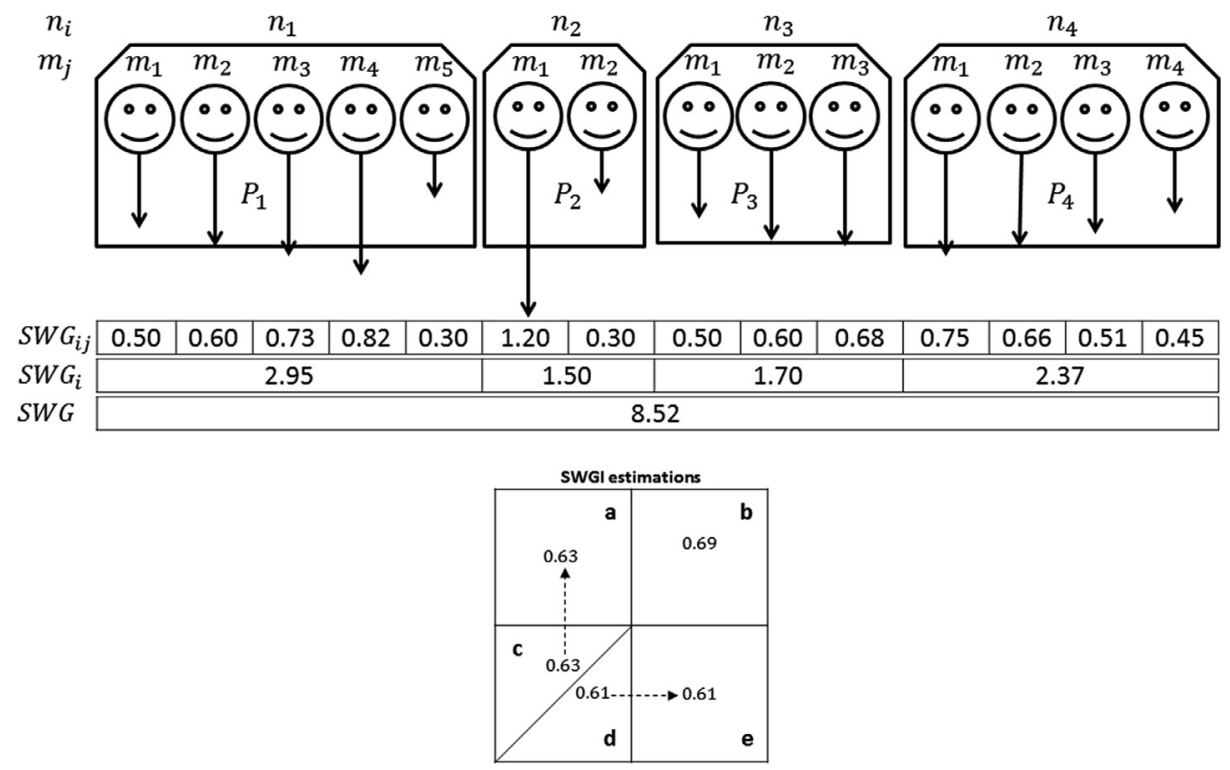

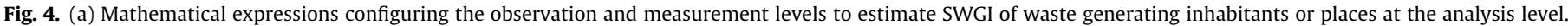

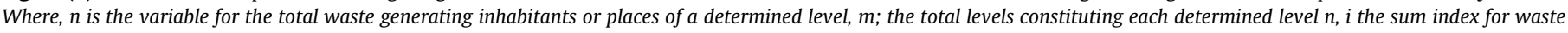

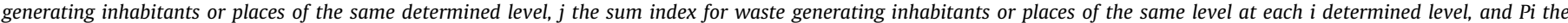

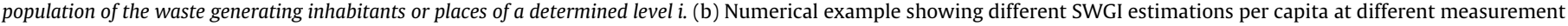

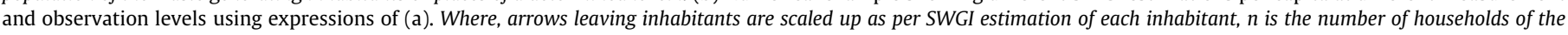
community and $m$ the number of inhabitants within each household.

\subsection{Identification and comparison of typologies of SWGI estimations}

Table 1 compares the main characteristics of the studies performed by GDR, JICA and INECO, all of which used different observation and measurement levels according to the way SWGI values were estimated in relation to their analysis levels. It shows the typology of SWGI estimation each study used according to Fig. 4a. Also compares SWGI results at the analysis and measure- ment levels as per income levels. For instance, the analysis level of GDR and the main clustering unit of the measurement level of JICA were both Bethania town, and the analysis level of JICA and the main clustering unit of the measurement level of INECO were both Panama district.

The approach used by JICA to estimate SWGI corresponds to a type (a) configuration, by INECO to a type (d) configuration which ended up being type (e), and by GDR, although it was meant to be 
Table 1

Comparison among the reviewed studies performed by GDR, JICA and INECO.

\begin{tabular}{|c|c|c|c|}
\hline Company & JICA & INECO & GDR \\
\hline $\begin{array}{l}\text { SWGI estimation type from } \\
\text { Fig. } 4 a\end{array}$ & $\mathrm{a}$ & d, e & $b, d$ \\
\hline Observation level & Household & Town & Household \\
\hline Measurement level & Town & $\begin{array}{l}\text { Defined by } \\
\text { socio- } \\
\text { economic } \\
\text { criteria }\end{array}$ & Community \\
\hline $\begin{array}{l}\text { Main clustering unit at the } \\
\text { measurement level/income } \\
\text { level/SWGI (kg/inh*d) }\end{array}$ & $\begin{array}{l}\text { Bethania } \\
\text { town/ } \\
\text { middle/ } \\
0.66\end{array}$ & $\begin{array}{l}\text { Panama } \\
\text { district/high/ } \\
1.55\end{array}$ & $\begin{array}{l}\text { Communities } \\
\text { of Bethania/ } \\
\text { high/0.96 }\end{array}$ \\
\hline $\begin{array}{l}\text { Analysis level/income level/ } \\
\text { SWGI (kg/inh*d) }\end{array}$ & $\begin{array}{l}\text { Panama } \\
\text { District/ } \\
\text { high/0.59 }\end{array}$ & $\begin{array}{l}\text { Country/ } \\
\text { upper- } \\
\text { middle/1.26 }\end{array}$ & $\begin{array}{l}\text { Bethania } \\
\text { town/middle/ } \\
0.76\end{array}$ \\
\hline
\end{tabular}

configured type (b), it ended up being type (d). The SWGI estimation of INECO and AAUD at the analysis level shows little variance, 1.26 and $1.30 \mathrm{~kg} \mathrm{inh}^{-1} \mathrm{~d}^{-1}$, respectively. JICA presented the lowest SWGI estimation at the Panama district analysis level $(0.59 \mathrm{~kg}$ $\left.i n h^{-1} d^{-1}\right)$, in contrast with INECO's value which was almost triple JICA's (1.55 $\mathrm{kg} \mathrm{inh}^{-1} \mathrm{~d}^{-1}$ ). JICA also presented the lowest SWGI estimation at the Bethania town measurement level $\left(0.66 \mathrm{~kg} \mathrm{inh}^{-1}\right.$ $\left.d^{-1}\right)$, very close to GDR's at its analysis level $\left(0.76 \mathrm{~kg} \mathrm{inh}^{-1} \mathrm{~d}^{-1}\right)$. GDR"s SWGI estimation at the measurement level $\left(0.96 \mathrm{~kg} \mathrm{inh}^{-1}\right.$ $\left.d^{-1}\right)$ was between its value at the analysis level $\left(0.76 \mathrm{~kg} \mathrm{inh}^{-1}\right.$ $d^{-1}$ ) and INECO's SWGI estimation at the country analysis level $\left(1.26 \mathrm{~kg} \mathrm{inh}^{-1} \mathrm{~d}^{-1}\right.$ ).

Comparisons of the SWGI estimation at the country analysis level of INECO (1.26) with literature values at the countrywide observation level by income levels (Table 2), show that INECO's SWGI estimation is over the average of upper-middle income level countries $\left(1.06 \mathrm{~kg} \mathrm{inh}^{-1} \mathrm{~d}^{-1}\right)$ and under the average of high-income level countries $\left(1.66 \mathrm{Kg} \mathrm{inh}^{-1} d^{-1}\right)$. This may be due to fallacies in the configuration of the observation and measurement levels. Unsteady economic growth rates and high social inequalities of Panama (Indexmundi, 2015) are also influencing factors, reflected in resource consumption and SWG patterns compared to other similar income level countries (IMF, 2018).

\subsection{Inference fallacies committed in the reviewed studies}

Methodological inference fallacies have been identified for SWGI estimations in the studies analysed (Table 3).

JICA committed the "individualistic fallacy" by generalizing the SWGI estimation to the whole Panama district directly from households. JICA did not considered that income level varies broadly among households of a district so it cannot be generalized at this analysis level directly from the households' observation level (Zohoori and Ghani, 2017).

Following the three criteria for the identification of the "ecological fallacy" proposed by Idrovo (2011), INECO committed condition (a) for ecological fallacy when using large-scale solid waste data surveyed in the landfill. JICA, INECO and GDR committed condition (b) for ecological fallacy when inferring the SWGI, estimated at the analysis level, to observation level entities, others than the ones aggregated at the measurement level. To avoid condition (b) for ecological fallacy, SWGI estimations should be directly surveyed from observation level entities, but this is a complex task to perform. To mitigate condition (b), the observation level should be as close to the measurement level as possible, and the measurement level should consider very diverse observation level entities. The SWGI estimation of GDR will be used as proper reference for the evaluation of condition (c) to ecological fallacy incurred by INECO and JICA, because GDR kept the closest relation between the measurement level i.e., households and the observation level i.e., inhabitants, it is therefore likely to be closer to the SWGI estimation type (a). JICA and INECO committed condition (c) for ecological fallacy. JICA mixed communities and towns together, handling them all as towns to cluster households based on their apparent income levels as clustering variable, whereas GDR used the actual income. INECO complies with all conditions for ecological fallacy, therefore as Idrovo (2011) proposed, this implies ecological fallacy perpetration.

Table 2

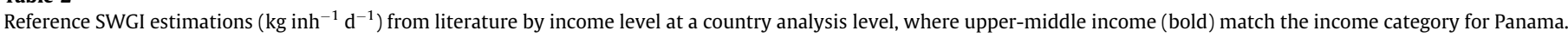

\begin{tabular}{|c|c|c|c|c|}
\hline \multirow[b]{2}{*}{ Source } & \multicolumn{4}{|c|}{ Income level $^{1}$} \\
\hline & High & Upper-middle & Lower-middle & Low \\
\hline Adamović et al., 2017 & 1.67 & 1.03 & 0.71 & - \\
\hline Shimura et al., 2001 & - & 0.95 & 0.67 & - \\
\hline OECD, 2008 & 1.53 & - & - & - \\
\hline Kofoworola and Gheewala, 2009 & - & - & 0.72 & - \\
\hline Afon and Okewole, 2007 & 1.80 & 1.24 & 0.70 & 0.50 \\
\hline Watson and Reichel, 2013 & 1.51 & - & - & - \\
\hline Wang and Wang, 2013 & - & 0.88 & - & - \\
\hline Wilson et al., 2012 & 1.67 & - & - & - \\
\hline Mejía, 2009 & 1.22 & - & - & - \\
\hline Hoornweg and Bhada, 2012 & - & 1.20 & 0.79 & 0.60 \\
\hline Kumar et al., 2009 & - & - & 0.39 & - \\
\hline Kaseva and Gupta, 1996 & - & - & - & 0.17 \\
\hline Thanh et al., 2010 & - & - & 0.78 & 0.58 \\
\hline Forouhar and Hristovski, 2012 & - & - & -- & 0.31 \\
\hline Troschinetz and Mihelcic, 2009 & 1.67 & - & 0.80 & - \\
\hline Achankeng, 2003 & - & - & - & 0.33 \\
\hline Kollikkathara et al., 2009 & 1.84 & 1.10 & - & - \\
\hline Din and Cohen, 2016 & - & - & - & 0.30 \\
\hline US EPA, 2014 & 1.99 & - & - & - \\
\hline Isugi and Niu, 2016 & - & - & - & 0.33 \\
\hline Average & 1.66 & 1.06 & 0.69 & 0.39 \\
\hline
\end{tabular}

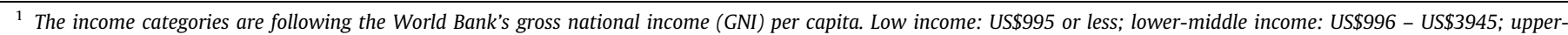

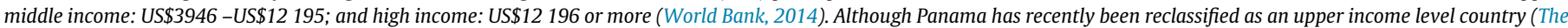

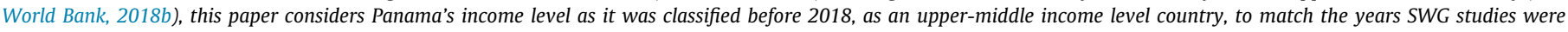
carried out. 
Table 3

Fallacies found in the last SWG measurement studies performed.

\begin{tabular}{llll}
\hline Fallacy & JICA & INECO & GDR \\
\hline 1. Ecological $(\mathrm{a}+\mathrm{b}+\mathrm{c}$ ) & & $\mathrm{X}$ & \\
a. Results obtained with ecological (population) data & & $x$ & \\
b. Data inferred to individuals from ecological levels & $x$ & $x$ & $x$ \\
c. Results obtained with individual data are contradictory & $x$ & $x$ & \\
2. Individualistic & $\mathrm{X}$ & & \\
3. Stage & & $\mathrm{X}$ & \\
4. Floating Population & $\mathrm{X}$ & \\
5. Linear Forecasting & $\mathrm{X}$ & $\mathrm{X}$ \\
6. Average Population & $\mathrm{X}$ & & \\
7. Mixed Spatial Levels & $\mathrm{X}$
\end{tabular}

3.3. Apart from the ecological and individualistic fallacies, other inference fallacies have been identified.

The "Stage fallacy" is the assumption that, after applying a correction coefficient, the results obtained at any stage of the SWM system e.g., final disposal, can also be considered valid for other stages e.g., waste generation. Correction coefficients are supposed to summarize in a single value the complexity of SWM system process subtleties at each of its stages. From the generation to the final disposal stage e.g. waste weight losses/gains during containerization due to excessive rain, underground waste market transactions by the waste transport civil servants or waste pickers of the streets, and informal recycling performed by waste pickers of the landfills (Scheinberg et al., 2011). However, in developing countries waste lost data along the SWM process is almost unaccountable since SWM information systems are seldom established. INECO incurred the Stage fallacy by equating their SWD study with a SWG study using a correction coefficient. Incurrence on this fallacy or poor estimation of the correction coefficient may be causal of a 3-fold SWGI estimation between INECO and JICA.

The "Floating Population fallacy" is a direct effect of studies using SWD values as SWG values. This fallacy represents unreliability of solid waste disposal intensity (SWDI) estimations derived from weighing collection trucks that dispose waste in landfills with unclear origins and undefined collection routes. The report on waste collection routes, commonly used by the local waste management authority (AAUD, 2014) for their waste collection activities, presents waste collection routes that either partially or totally mix communities. This makes it almost impossible to estimate the population from which waste is collected and disposed of. INECO committed the Floating Population fallacy by estimating SWDI using data from this report to select waste collection trucks to be sampled at the landfill, but also using fixed population values at the town level, not precisely belonging to mixed communities included in each route.

The "Linear Forecasting fallacy" presumes that future change will be a simple and steady extension of past trends, i.e. estimating SWGI over years without considering SWG and population of the analysis level, both unpredictable extensive variables with many factors shaping their context (Pereira et al., 2006). JICA committed this fallacy when linearly forecasting a SWGI estimation for Panama district and its constituting towns in 2015 based on results obtained in 2002. When subjected to similar changes, the SWM system may behave in similar patterns over time and past events can lead to predictions about its behaviour, however the timing or frequency of such behaviour cannot be predicted. Forecasting SWGI values considering no changes in the state of a SWM system over years will give results quite different from the reality, because over time the environment pushes the SWM system far away from its equilibrium state into chaos which can result in sudden, unpredictable changes (Seadon, 2010).
The "Mixed Spatial Levels fallacy" is the introduction of a measurement level composed of geopolitically undefined spatial levels to cluster observation level entities (inhabitants or places). This fallacy was committed by JICA when clusters were formed by mixing towns and communities, under the assumption that they were at the same spatial level. Also, a combination of the Individualistic and Mixed Spatial Levels fallacies may have caused JICA's low SWGI estimation, where observation levels (households) and measurement levels (undefined between communities and towns) are very close to each other.

The "Average Population fallacy" occurs when using multilevel estimations of type (b) without accounting for the actual population of the surveyed observation level. GDR committed this fallacy by using average inhabitants per household instead of actual's to estimate the SWGI, probably because of insufficient budget to execute this task.

The reason for the difference between GDR's and JICA's SWGI estimations of the analysis level and main clustering unit at the measurement level, respectively, may be an offset between the effects of the Average Population fallacy incurred by GDR and the Mixed Spatial levels fallacy incurred by JICA.

The effect of the Average Population fallacy incurred by GDR is a lower SWGI estimation, because instead of carrying on a multilevel estimation of type (b), it uses an estimation of type (d) by considering the same population at each measurement level.

\section{Conclusions and recommendations}

SWM systems in developing countries are incipient and far from efficient when compared with developed countries. One of the main barriers to embedding robust SWM systems is the lack of data to understand the SWM situation. To create, develop and implement SWM system plans, diagnoses of the current waste management systems are carried out by companies contracted by the government in power. SWG surveys play a key role in those diagnoses; useful indicators such as SWGI can be obtained for planning sustainable SWM systems. However, methodologies to estimate SWGI often contain inference fallacies that undermine the reliability of results. SWM plans based on these results propose solutions that are difficult to implement because they are derived from incongruent SWGI estimations which do not represent the actual SWM system situation.

This paper reviewed the methodological approaches used for SWG surveying by the local SWM authority (AAUD) and three official studies performed in Panama. The generalized approach used by AAUD to estimate SWGI produces ineffective allocation of technical, logistic, economic and human resources to the SWM system (AAUD, 2018; ANAM, 2002; La Prensa, 2018, 2011; Linowes and Brown, 2006). Seven inference fallacies (ecological, individualistic, stage, floating population, linear forecasting, average population and mixed spatial levels) were identified and allocated to each reviewed study. It was determined that foreign companies committed three of the seven inference fallacies presented, while one was committed by the local entity. Endogenous knowledge and expertise played an important role in the latter. INECO committed the ecological, stage and floating population fallacies; JICA committed the individualistic, linear forecasting and mixed spatial levels fallacies while GDR committed the average population fallacy.

When there is a clear distinction between the spatial level at which the SWG is surveyed (observation level), the spatial level at which the SWG is aggregated (measurement level) and the spatial level at which the SWGI estimation is expressed (analysis level), then population distribution is taken into account (Loney and Nagelkerke, 2014). In this case, the use of explanatory variables to find a correlation with the SWG from household to country 
e.g. with family income or with GDP data (Kinnaman, 2009), respectively compensates the effect exerted by the uncertainty of population distribution over SWGI estimations. It also opens the possibility to cluster measurement levels. Differencing the analysis and observation levels and introducing the measurement level as an auxiliary resource of the estimation is an advantage to reach more accurate SWGI estimates.

Multilevel SWG studies appear to present more robust information than studies conducted in other ways. This offers a more comprehensive framework for understanding how places can affect people or, alternatively, how people can affect places. The data quality obtained when characterizing entities (inhabitants or places) at several spatial levels using explanatory variables e.g. education level, ethnic diversity, employment rate, healthcare access and financial development to estimate the SWGI, renders more reliable and accurate SWM plans.

\section{Declaration of Competing Interest}

The authors declare that they have no known competing financial interests or personal relationships that could have appeared to influence the work reported in this paper.

\section{Acknowledgements}

This original work was supported by the Government of Panama, the Universidad Tecnológica de Panamá (UTP) and the Panamanian Secretaría Nacional de Ciencia, Tecnología e Innovación (SENACYT). The authors acknowledge the financial support of the Spanish Ministry of Science, Innovation and Universities, through the "María de Maeztu" program for Units of Excellence (CEX2019-000940-M). The authors are grateful to private companies and public institutions for providing valuable information on available studies. The authors declare no competing financial interests. This work reflects the authors' view only.

\section{References}

AAUD, 2018. Ejecución Presupuestaria de Ingresos y Gastos [WWW Document]. URL http://www.aaud.gob.pa/docs/Articulo10/Informes/Informe_FEB2018.pdf (accessed 4.29.18).

AAUD, 2014. Rutas de Recolección [WWW Document]. URL http://www.aaud.gob. $\mathrm{pa} /$ index.asp? sec=Rutas\&id=ADiurno (accessed 7.10.18).

Achankeng, A.E., 2003. Globalization, Urbanization and Municipal Solid Waste Management in Africa, in: African Studies Association of Australasia and the Pacific. Adelaide, p. 22.

Adamović, V.M., Antanasijević, D.Z., Ristić, M.Đ., Perić-Grujić, A.A., Pocajt, V.V., 2017. Prediction of municipal solid waste generation using artificial neural network approach enhanced by structural break analysis. Environ. Sci. Pollut. Res. 24 (1), 299-311. https://doi.org/10.1007/s11356-016-7767-x.

Addison, S.R., 2000. A method to illustrate the extensive and intensive properties of thermodynamic variables [WWW Document]. URL https://faculty.uca.edu/ saddison/GordonConference/GordonConferencePoster.pdf (accessed 6.4.18).

Afon, A.O., Okewole, A., 2007. Estimating the quantity of solid waste generation in Oyo. Nigeria. Waste Manag. Res. 25 (4), 371-379. https://doi.org/10.1177/ 0734242 X07078286.

Alker Jr., H.R., 1974. A typology of ecological fallacies [WWW Document]. Soc. Ecol. URL https://eurekamaghttps//www.econbiz.de/Record/a-typology-ofecological-fallacies-alker-hayward/10001842677com/research/026/127/ 026127182.php (accessed 6.9.18).

ANAM, 2002. La Basura: Un problema de todos [WWW Document]. URL https:// www.jica.go.jp/project/spanish/panama/2515031E0/data/pdf/5-45.pdf (accessed 12.5.18)

Bandara, N.J.G.J., Hettiaratchi, J.P.A., Wirasinghe, S.C., Pilapiiya, S., 2007. Relation of waste generation and composition to socio-economic factors: A case study. Environ. Monit. Assess. 135 (1-3), 31-39. https://doi.org/10.1007/s10661-0079705-3.

Blakely, T., Woodward, A.J., 1999. Ecological effects in multi-level studies. J. Epidemiol. Community Health 54, 367. https://doi.org/10.1136/jech.54.5.367.

Blakely, T.A., Woodward, A.J., 2000. Ecological effects in multi-level studies. J. Epidemiol. Community Health 54, 367-374. https://doi.org/ 10.1136/jech.54.5.367.
Buenrostro, O., Bocco, G., Vence, J., 2001. Forecasting generation of urban solid waste in developing countries - A case study in Mexico. J. Air Waste Manag. Assoc. 51 (1), 86-93. https://doi.org/10.1080/10473289.2001.10464258.

DEFRA, 2013. Environmental Reporting Guidelines [WWW Document]. URL www.gov.uk/defra (accessed 4.3.18)

Din, G.Y., Cohen, E., 2016. Modeling Municipal Solid Waste Management in Africa: Case Study of Matadi, the Democratic Republic of Congo 141-141. In: Solid Waste Management Policy and Planning for a Sustainable Society. Apple Academic Press. https://doi.org/10.1201/b19424-10.

Forouhar, A., Hristovski, K.D., 2012. Characterization of the municipal solid waste stream in Kabul, Afghanistan. Habitat Int. 36 (3), 406-413. https://doi.org/ 10.1016/j.habitatint.2011.12.024.

Fujimoto, S., Mizuno, T., Ohnishi, T., Shimizu, C., Watanabe, T., Fujimoto, S., Mizuno, T., Ohnishi, T., Shimizu, C., Watanabe, T., 2015. Geographic Dependency of Population Distribution. Springer Proceedings in Complexity. https://doi.org/ 10.1007/978-3-319-20591-5 14.

Giampietro, M., Mayumi, K., Ramos-Martin, J., 2009. Multi-scale integrated analysis of societal and ecosystem metabolism (MuSIASEM): Theoretical concepts and basic rationale. Energy 34 (3), 313-322. https://doi.org/10.1016/j. energy.2008.07.020.

Guerrero, L.A., Maas, G., Hogland, W., 2013. Solid waste management challenges for cities in developing countries. Waste Manag. 33 (1), 220-232. https://doi.org/ 10.1016/j.wasman.2012.09.008.

Hoornweg, D., Bhada, P., 2012. What a Waste. A Global Review of Solid Waste Management. Urban Dev. Ser. Knowl. Pap. 281, 44 p. https://doi.org/10.1111/ febs. 13058.

Idrovo, A.J., 2011. Three criteria for ecological fallacy. Environ. Health Perspect. https://doi.org/10.1289/ehp.1103768.

IMF, 2018. World Economic Outlook: Cyclical Upswing, Structural Change [WWW Document]. Int. Monet. Fund. URL https://www.imf.org/external/pubs/ft/weo/ 2009/01/pdf/text.pdf.

Indexmundi, 2015. Countries ranked by GINI index (World Bank estimate) [WWW Document]. URL https://www.indexmundi.com/facts/indicators/SI.POV.GINI/ rankings (accessed 2.21.19).

INEC, 2016. Comentarios sobre la economía panameña [WWW Document]. URL https://www.contraloria.gob.pa/inec/archivos/P8371Comentarios.pdf (accessed 12.7.17).

INEC, 2006. Estimación de la población en la provincia de Panamá, por sexo, según distrito y corregimiento [WWW Document]. URL https://www.contraloria.gob. $\mathrm{pa} /$ inec/SINAMP/pdf/Panama.pdf (accessed 1.8.18).

INECO, 2017. Plan Nacional de gestión integral de residuos 2017-2027 [WWW Document]. URL http://aaud.gob.pa/plangestion//Docs/ANEXOS/20170731_E 1. 3.3.3.5_Propuesta Nuevo Modelo de Gestion_v3.pdf (accessed 4.29.18).

Isugi, J., Niu, D., 2016. Research on Landfill and Composting Guidelines in Kigali City, Rwanda Based on China's Experience. https://doi.org/10.7763/IPCBEE.

James, W., 1890. The Principles of Psychology, Volume 1.

JICA, 2005. Supporting Capacity Development in Solid Waste Management in Developing Countries; Towards Improving Solid Waste Management Capacity of Entire Society [WWW Document]. URL http://open_jicareport.jica.go.jp/pdf/ 11795846.pdf (accessed 11.26.17).

JICA, 2003. The Study on Solid Waste Management Plan for Municipality of Panama in the Republic of Panama [WWW Document]. URL http://open_jicareport.jica. go.jp/pdf/11712841_01.pdf (accessed 4.29.18).

Kaseva, M.E., Gupta, S.K., 1996. Recycling - An environmentally friendly and income generating activity towards sustainable solid waste management. Case study Dar es Salaam City, Tanzania. Resour. Conserv. Recycl. 17 (4), 299-309. https:// doi.org/10.1016/S0921-3449(96)01153-6.

Kinnaman, T.C., 2009. The economics of municipal solid waste management. Waste Manag. 29 (10), 2615-2617. https://doi.org/10.1016/j.wasman.2009.06.031.

Kofoworola, O.F., Gheewala, S.H., 2009. Estimation of construction waste generation and management in Thailand. Waste Manag. 29 (2), 731-738. https://doi.org/ 10.1016/j.wasman.2008.07.004.

Kohberger, R.C., Everitt, B.S., 1994. Cluster analysis. Technometrics 36 (2), 216. https://doi.org/10.2307/1270235.

Kollikkathara, N., Feng, H., Stern, E., 2009. A purview of waste management evolution: Special emphasis on USA. Waste Manag. 29 (2), 974-985. https://doi. $\operatorname{org} / 10.1016 /$ j.wasman.2008.06.032.

Kumar, S., Bhattacharyya, J.K., Vaidya, A.N., Chakrabarti, T., Devotta, S., Akolkar, A.B., 2009. Assessment of the status of municipal solid waste management in metro cities, state capitals, class I cities, and class II towns in India: An insight. Waste Manag. 29 (2), 883-895. https://doi.org/10.1016/j.wasman.2008.04.011.

La Prensa, 2018. Basura, un grave problema [WWW Document]. URL https://www. prensa.com/politica/Basura-grave-problema_0_2722977869.html (accessed 1.8.18).

La Prensa, 2011. La basura, un negocio jugoso [WWW Document]. URL https:// impresa.prensa.com/panorama/basura-negocio-jugoso_0_3163933628.html (accessed 1.8.18).

Linowes, R., Brown, M., 2006. The Tropical Waste Dilemma: waste management in Panama. Int. J. Emerg. Mark. 1, 101-112. https://doi.org/10.1108/ $17468800610674453 / /$.

(Oecd) Linster, M., 2003. OECD Environmental Indicators: development, measurement and use. SNUC - Sist. Nac. Unidades Conserv. 25, 37. https:// doi.org/10.1016/j.infsof.2008.09.005.

Loney, T., Nagelkerke, N.J., 2014. The individualistic fallacy, ecological studies and instrumental variables: a causal interpretation. https://doi.org/10.1186/1742 7622-11-18. 
Mandelbrot, B., 1967. How long is the coast of Britain? Statistical self-similarity and fractional dimension. Science (80-.) 156 (3775), 636-638. https://doi.org/ 10.1126/science: 156.3775 .636$.

Matuszewski, A., 2002. In: Intelligent Information Systems 2002. Physica-Verlag HD, Heidelberg, pp. 227-236. https://doi.org/10.1007/978-3-7908-17775_24.

Mejía, C.A.Z., 2009. Metodología de diseño para la recogida de residuos sólidos urbanos mediante factores punta de generación: Sistemas de caja fija (SCF). Ing. e Investig. 29, 119-126.

Molina-Azorín, J.F., Pereira-Moliner, J., López-Gamero, M.D., Pertusa-Ortega, E.M., Tarí, J.J., 2019. Multilevel research: Foundations and opportunities in management. BRQ Bus. Res. Q https://doi.org/10.1016/j.brq.2019.03.004.

Moon, G., Subramanian, S. V, Jones, K., Duncan, C., Twigg, L., 2005. Area-based studies and the evaluation of multilevel influences on health outcomes, Handbook of health research methods: Investigation, measurement and analysis.

MUPA, 2018. Estudio de caracterización puntual y dinámica de la generación y composición de los residuos sólidos urbanos por conglomerados de lugares poblados del corregimiento de Betania según sus características sociodemográficas [WWW Document]. URL http://gestionderesiduos.com. $\mathrm{pa} /$ caracterizacion/EstudioBethania.pdf (accessed 7.10.18).

Nottale, L., 2010. Scale relativity and fractal space-time: Theory and applications. Found. Sci. 15 (2), 101-152. https://doi.org/10.1007/s10699-010-9170-2.

OECD, 2008. Key environmental indicators, OECD Environment Directorate. https://doi.org/10.2110/pec.72.02.0001.

Pereira, Â.G., Vaz, S.G., Tognetti, S., 2006. Interfaces between Science and Society.

Ragossnig, A.M., Vujić, G., 2015. Challenges in technology transfer from developed to developing countries. Waste Manag. Res. 33 (2), 93-95. https://doi.org/ $10.1177 / 0734242 \times 15569403$.

Robinson, W.S., 1950. Ecological correlations and the behaviors of individuals. Am. Sociol. Rev. 15, 351-357. https://doi.org/10.1093/ije/dyn357.

Scheinberg, A., Spies, S., Simpson, M.H., Mol, A.P.J., 2011. Assessing urban recycling in low- and middle-income countries: Building on modernised mixtures. Habitat Int. 35 (2), 188-198. https://doi.org/10.1016/j.habitatint.2010.08.004.

Seadon, J.K., 2010. Sustainable waste management systems. J. Clean. Prod. 18 (1617), 1639-1651. https://doi.org/10.1016/j.jclepro.2010.07.009.

Selvin, H.C., 1958. Durkheim's Suicide and Problems of Empirical Research. Am. J. Sociol. 63 (6), 607-619. https://doi.org/10.1086/222356.

Shimura, S., Yokota, I., Nitta, Y., 2001. Research for MSW flow analysis in developing nations. J. Mater. Cycles Waste Manag. 3, 48-59.

Subramanian, S.V., Jones, K., Kaddour, A., Krieger, N., 2009. Revisiting Robinson: The perils of individualistic and ecologic fallacy. Int. J. Epidemiol. 38, 342-360. https://doi.org/10.1093/ije/dyn359.
Thanh, N.P., Matsui, Y., Fujiwara, T., 2010. Household solid waste generation and characteristic in a Mekong Delta city, Vietnam. J. Environ. Manage. 91 (11), 2307-2321. https://doi.org/10.1016/j.jenvman.2010.06.016.

World Bank, 2014. Gross national income per capita 2014, Atlas method and PPP Gross national income per capita 2013, Atlas method and PPP (Issue July). http://databank.worldbank.org/data/download/GNIPC.pdf.

The World Bank, 2018a. What is the World Bank Atlas method? - World Bank Data Help Desk [WWW Document]. URL https://datahelpdesk.worldbank. org/knowledgebase/articles/77933-what-is-the-world-bank-atlas-method (accessed 7.9.18).

The World Bank, 2018b. New country classifications by income level: 2018-2019| The Data Blog [WWW Document]. URL https://blogs.worldbank.org/opendata/ new-country-classifications-income-level-2018-2019 (accessed 7.9.18).

Troschinetz, A.M., Mihelcic, J.R., 2009. Sustainable recycling of municipal solid waste in developing countries. Waste Manag. 29 (2), 915-923. https://doi.org/ 10.1016/j.wasman.2008.04.016.

US EPA, 2014. Municipal Solid Waste Generation, Recycling, and Disposal in the United States: Facts and Figures for 2012. US Environ. Prot. Agency 1-13. https://doi.org/EPA-530-F-14-001.

Voss, B. de L., Pfitscher, E.D., da Rosa, F.S., Ribeiro, M. de S., 2013. Solid waste environmental disclosures of public companies in Brazil of environmentally sensitive industries/Evidenciacao ambiental dos residuos solidos de companhias abertas no Brasil potencialmente poluidoras.(articulo en ingles). Rev. Contab. Financ. 24, 125. https://doi.org/10.1590/S1519-70772013000200004.

Wang, H., Wang, C., 2013. Municipal solid waste management in Beijing: characteristics and challenges. Waste Manag. Res. 31 (1), 67-72. https://doi. org/10.1177/0734242X12468199.

Watson, D., Reichel, A., 2013. Municipal Waste Management in the United Kingdom.

Wilson, D.C., Rodic, L., Scheinberg, A., Velis, C.A., Alabaster, G., 2012. Comparative analysis of solid waste management in 20 cities. Waste Manag. Res. 30 (3), 237254. https://doi.org/10.1177/0734242X12437569.

Wilson, D.C., Velis, C.A., 2014. Cities and waste: current and emerging issues. Waste Manag. Res. 32 (9), 797-799. https://doi.org/10.1177/0734242X14547125.

Winzar, H., 2015. The ecological fallacy: How to spot one and tips on how to use one to your advantage. Australas. Mark. J. 23, 86-92. https://doi.org/10.1016/j. ausmj.2014.12.002.

Wittwer, J., Nückles, M., Renkl, A., 2008. Is underestimation less detrimental than overestimation? The impact of experts' beliefs about a layperson's knowledge on learning and question asking. Instr. Sci. 36, 27-52. https://doi.org/10.1007/ s11251-007-9021-X.

Zohoori, M., Ghani, A., 2017. Municipal Solid Waste Management Challenges and Problems for Cities in Low-Income and Developing Countries. Int. J. Sci. Eng. Appl. 6, 039-048. https://doi.org/10.7753/IJSEA0602.1002. 